\title{
Las organizaciones no gubernamentales: su papel en las políticas públicas *
}

John Casey *

\section{Presentación}

Este estudio forma parte de una investigación doctoral sobre el papel que desempeñan las organizaciones no gubernamentales (ONG) en el proceso de elaboración de políticas públicas. El artículo se enfoca desde una perspectiva propiamente de análisis de políticas públicas, la cual se contrastará en la disertación final con otros enfoques sobre acciones colectivas, tales como los grupos de interés, los movimientos sociales, y la elección pública. La investigación también abarca un análisis de la dimensión del sector de las ONG en España y Cataluña.

\section{Introducción}

Las organizaciones no gubernamentales (ONG) ${ }^{1}$ tienen una larga tradición ${ }^{2}$, pero hasta hace poco han sido consideradas como un elemento marginal en sociedades dominadas por la dinámica entre el Estado, el mercado y, en algunos países, la Iglesia. Sin embargo, en las últimas dos décadas las ONG han experimentado un crecimiento exponencial en su actividad e influencia y han afrontado cambios significativos que han redefinido su papel social (Drucker, 1990).

Tanto en el marco del llamado Estado de bienestar, como en el del intervencionismo estatal, se están buscando siempre nuevas fórmulas de organización para la prestación de servicios y para fomentar la participación social en los procesos democráticos. Las ONG parecen haber ofrecido soluciones aceptables a la mayoría de los estamentos de la sociedad y ninguna ideología acapara el discurso en favor de potenciarlas: la derecha las ve como una fuente importante de iniciativa extra-gubernamental que puede contrarrestar el poder del Estado y privatizar la prestación de servicios estatales; la izquierda las ve como un paradigma del activismo de base que puede trabajar conjuntamente con las administraciones para asegurar la prestación eficaz de bienes sociales.

Asimismo, el auge de las ONG se debe ver no solamente como un hecho espontáneo -l resultado de un crecimiento del activismo y de la participación cívica - sino también como la consecuencia de políticas de fomento de determinados go- biernos que las consideran instrumentos importantes para impulsar sus objetivos.

Este incremento de su papel ha ido acompañada por un aumento del interés por parte de comentaristas e investigadores ${ }^{3}$ que se han centrado mayoritariamente en teorías que explican su origen y su papel en la prestación de servicios o en modelos de gestión. Se ha prestado, sin embargo, menor atención al papel político de las ONG y la bibliografía sobre ellas suele liquidar este tema con pocas palabras en el prefacio o en los apartados introductorios y parecen dar por descontado que las ONG pueden tener una influencia relevante en la elaboración de las políticas públicas.

En este artículo intento acercarme más a dicho papel político. Si existe una pluralidad de actores en el proceso de elaboración de políticas públicas y si se pueden identificar las ONG como posibles actores extra-gubernamentales. ¿Cómo desempeñan, entonces, dicho papel y qué posibilidades tienen de ser actores significativos en el proceso?

\section{Los orígenes de las $\mathrm{ONG}$}

El número de ONG ha aumentado considerablemente en las últimas dos décadas y su influencia dentro del Estado de bienestar se ha ampliado, lo que ha creado una relación tanto de cooperación como de competencia con las instituciones gubernamentales en la prestación de servicios y en la elaboración de las políticas públicas. ¿A qué se debe su desarrollo y auge? ¿Por qué las instituciones comparten sus responsabilidades con las ONG si ya gozan de la legitimidad y la autoridad del sistema político?

\subsection{Lógicas economicistas}

WEISBROD sostenía que los bienes públicos proporcionados por el Estado a cambio de las contribuciones de los ciudadanos se dirigen, por razones políticas y económicas, al contribuyente medio, circunstancia que deja un mercado de demanda no cubierta" para la producción de bienes públicos destinados a los que tienen necesidades que no se ajustan a la media. Eso pue- 
de darse tanto en las clases altas de la sociedad, integradas por gente dispuesta a comprar dichos servicios a través de empresas privadas (p. ej. los que mandan a sus hijos a escuelas privadas), como en las clases bajas, que se movilizan para organizar una provisión alternativa, normalmente a través de ONG (HANSMANN, 1987; Wolch, 1990; LyONS, 1993).

Entre las críticas a la lógica de WEISBROD destacan aquellas que consideran que ésta, aun explicando por qué las ONG prestan los mismos bienes y servicios públicos que las administraciones, no explican por qué lo hacen también en competencia con empresas privadas (p.ej. además de las escuelas privadas para la clase alta, existen escuelas sin fines de lucro -un tipo de ONG - que también prestan servicios al mismo mercado). Para abordar este tema, HansmanN propone el concepto "contratos incompletos ${ }^{4}$ según el cual los consumidores tienen una preferencia por las ONG cuando las administraciones fracasan en la prestación de servicios universales porque las empresas privadas no ofrecen garantías que no harán primar sus intereses económicos (Hansmann, 1987; Dimaggio y ANHEIER, 1990; LyONS, 1993).

Pero estas dos teorías sólo explican la demanda de los consumidores, y no ofrecen explicaciones sobre por qué existe también una preferencia por una oferta organizada en forma de ONG. ¿Qué beneficio pueden éstas organizaciones ofrecer si no distribuyen las ganancias obtenidas por la prestación de servicio (o sea, si actúan sin fines de lucro)? Estelle James sostiene que es ante todo un beneficio ideológico o de misión religiosa el que fomenta la creación de las ONG (LYONS, 1993); pero también el acceso que dan las ONG a ciertas ventajas fiscales, incluidas las subvenciones, les confiere una superioridad económica en algunos sectores donde existe también la opción de organización empresarial (WolCH, 1990).

Las teorías económicas analizan la creación de las ONG de prestación de servicios; sin embargo, no explican nítidamente ni la existencia de ONG de militancia política, ni las que organizan actividades culturales y deportivas, ni el fomento de las ONG por parte del Estado (las ONG y el Estado siempre deberían competir según la lógica economicista), ni tampoco el auge de las ONG en las últimas décadas.

\subsection{Lógicas político-sociológicas}

Varias autores atribuyen el auge de las ONG al entramado de dinámicas que han resultado en un retroceso de la intervención pública en el contexto de la llamada ecrisis del Estado de bienestarn. Los factores más relevantes suelen ser una combinación de las exigencias de un nuevo pluralismo —en una sociedad más compleja, más corporatista, resulta necesario organizarse para hacerse oír - y una llamada a la eficacia organizativa y económica de la prestación de servicios. HOOD y SCHUPPERT (1988) y SuBIRATS (1992) identifican las características de la situación socio-política actual que explican la preferencia por las ONG y el fomento de su desarrollo:

- El crecimiento de la heterogeneidad política, étnica y religiosa existente en la sociedad actual y la creciente afirmación política de los grupos minoritarios.

- La proliferación de demandas más diferenciadas y complejas en relación a los servicios públicos.

- La incorporación de las preferencias de los clientes en el proceso de prestación de servicios y una mayor preocupación por la calidad de los servicios que por la cantidad.

- La actitud de desconfianza hacia las burocracias públicas y partidos políticos tradicionales, relacionada con una mayor percepción de la corrupción.

- El aumento de la capacidad auto-organizativa de la población de los países desarrollados.

- La creciente preocupación por crear modalidades de prestación de servicios que sean más eficientes y que estén libres de la rigidez normativa de las administraciones.

Esta relación de factores ilustra bien la tendencia actual de conferir a los enfoques sobre el auge de las ONG — tanto desde el punto de vista del ciudadano/consumidor como desde el de las administraciones que promueven políticas en pro del fomento de las $\mathrm{ONG}$ - un carácter pluralista y progresista. Parecen senalar tanto la deseabilidad, como la inevitabilidad de la "tercera-sectorización" del sector público.

Sin embargo, hay pocos datos empíricos que demuestren que las ONG ofrecen lo que prometen (DIMAGGIO y ANHEIER, 1990). Las ONG pueden estar bien financiadas, gozar de una gestión eficaz, ser sensibles a las necesidades de la comunidad y ser capaces de responder a los cambios; pero también pueden estar infra-financiadas, obligadas a amendigar" para captar fondos en el mundo competitivo del mecenazgo y pueden ofrecer servicios de segunda clase con técnicos poco formados y en situaciones laborales precarias. Además, no ofrecen la misma transparencia que las administraciones.

Las ONG compiten con el Estado, pero pueden constituir una competencia tanto leal que impulsa a las administraciones a ser más eficientes, como desleal que ofrece una alternativa con apariencia de ser democrática, transparente, eficaz y sensible, pero sin garantías de serlo en realidad. Ofreciendo esta alternativa deslegitiman la acción del Estado.

Tampoco debería olvidarse que el fomento de las ONG es también es un arma de las fuerzas conservadoras. Bajo la etiqueta de "privatización" existe toda una corriente que pretende desplazar la responsabilidad de la prestación de servicios al 
sector privado, el cual no está compuesto solamente por ONG, sino también por empresas privadas que priman criterios económicos por encima de los de equidad y justicia social. Paradójicamente, las raíces intelectuales del aumento de las ONG en las últimas décadas surgen tanto del neoliberalismo a ultranza de Reagan y Thatcher, como de los movimientos populares progresistas (HENIG, 1990).

\section{Como afirman DiMAGGio y ANHEIER:}

-[Las ONG] son las protectoras tanto del pluralismo como del privilegio, instrumentos de democracia y de control, fuentes de innovación y de parálisis, tanto socio como competencia para el Estado. (1990: 153)

\section{Definiciones de ONG y alcance del sector}

Hasta hace relativamente poco no se hablaba de "ONG" $\longrightarrow 0$ de las otras etiquetas que analizaremos a continuación - en sentido colectivo, sino de asociaciones de caridad, hospitales, instituciones culturales, etc., como entidades distintas que tenían poco en común (DrUCKER, 1990). Paralelamente al auge de estas organizaciones y de la investigación de su papel en la sociedad, ha ido aumentando la conciencia de que constituyen un sector de entidades con estructuras y fines comparables.

Pero los investigadores no han podido establecer una designación o definición única de estas organizaciones, lo que ha dado lugar a una ensalada de terminologías y un 'popurrí' de definiciones" (6 y PESTOFF 1993:1). Estas incluyen: términos norteamericanos y anglosajones como los calificativos non-profit (no lucrativa o sin ánimo de lucro), community-based (comunitaria o basada en la comunidad), charity (caridad), voluntary (voluntario), independent (independiente) e informal y nombres colectivos como third party government (gobierno por terceros), third sector (tercer sector) y shadow government (gobierno en la sombra) (Wolch, 1990; LoHmanN, 1993); términos europeos como el francés économie sociale, los alemanes gemeinnützige (bienestar común) y gemeinwirtschaftliche unternebmen (economía común), el inglés non-statutory sector (sector no estatutario) y el equivalente a administración pública indirecta. de uso en Finlandia, Alemania, y Dinamarca (Kramer, 1981; 6 y Pestoff, 1993; ANHEIER y Seibel, 1990; Salamon y ANHEIER, 1992); el australiano community services sector (sector de servicios comunitarios) y, por último, "asociacionismo" de uso común en Cataluña y España (AA.VV, 1992b). Dichos términos describen conceptos solapados, pero algo distintos, diferenciados según distintos identidades jurídicas, estilos de participación y de gestión, grado de separación del Estado y papeles políticos, económicos o sociales 5 .
Este artículo no es el foro adecuado para analizar estos matices $^{6}$. Para denominar las entidades he elegido el término ONG por ser uno de los más usuales en la actualidad y, sobre todo, porque permite poner de manifiesto la separación de estas entidades de las instituciones estatales en la arenas políticos.

\section{1. ¿Qué es una ONG?}

Las definiciones de las ONG suelen basarse en características concretas que combinan aspectos jurídicos ${ }^{7}$, sociales, funcionales y económicos (Continente, 1992; Petrus, 1991; Salamon y ANHEIER, 1992a). Las características más citadas son:

- Estructura formalizada.

- Autonomía institucional con respecto a las administraciones.

- Sin fines de lucro.

- Valores asociativos y organización participativa.

- Participación del voluntariado, pero también de profesionales contratados.

- Actuación en los ámbitos de la salud, la cultura, la educación, el ocio y las acciones sociales con el objetivo de mejorar la calidad de vida de los clientes.

Pero inmediatamente surgen problemas si se intenta analizar dichas características como valores absolutos. Muchas veces resulta difícil valorar si una entidad reúne o no alguna de las características, razón por la cual éstas deben verse como valores relativos ubicados en sus respectivos continuos.

El continuo más difícil de definir es el de la autonomía de las administraciones; es decir, si de hecho la organización tiene una identidad jurídica y un ámbito de actuación independiente para poder considerarse "privada" $y$ "no-gubernamental" o si forma parte de lo que se considera "público" $y$ agubernamental ${ }^{8}$. ¿Puede una entidad ser no-gubernamental e independiente si, por ejemplo, fue fundada a iniciativa institucional, tiene representantes de las administraciones en su consejo directivo, recibe la mayoría de sus ingresos de subvenciones estatales y se ajusta a normativas restrictivas sobre su esfera de acción?

Es en este intento de separar lo gubernamental de lo nogubernamental donde surge el concepto de "tercer sectorn (y los términos afines). La definición que se suele dar del tercer sector ${ }^{9}$ es la de un sector que existe "por omisión:

-La lógica de un tercer sector se basa en la insuficiencia de los otros dos. La administración -el primer sector- proporciona bienes públicos, pero tiene limitaciones; el mercado -el segundo sector- permite la elección individual, pero no proporciona bienes públicos; el tercer sector no tiene ni la autoridad de la administración, ni 
el mercantilismo del mercado, pero permite la elección individual y proporciona bienes públicos. ... el tercer sector funciona porque los otros no lo hacen." (GIES, 1990; vii)

El tercer sector, por tanto, ocupa el espacio conceptual en la frontera que delimita las instituciones públicas del primer sector y las privadas del segundo. Evidentemente, ocupar tal espacio no confiere nitidez a su definición y los varios intentos de establecer una separación entre los sectores sobre un hipotético continuo entre lo público/gubernamental y lo privado/no gubernamental sólo sirven para poner de manifiesto las dificultades que ello implica.

En los dos extremos de dicho continuo las definiciones serían del modo siguiente:

- Lo público abarca todas aquellas actividades realizadas por las administraciones a cargo del gasto público; ejerciendo el poder, autoridad y legitimidad que confiere el sistema político y la administración.

- Lo privado abarca actividades realizadas con fines lucrativos por entidades que no son de propiedad estatal, que no se financian a través de impuestos y cuyos responsables no son escogidos ni por los ciudadanos ni por el gobierno.

Entre los dos extremos Bozeman (1987) ofrece una concepción multidimensional de la separación entre lo público y lo privado que incluye:

- El grado de participación fiscal de las administraciones.

- El grado de representación política y del control sobre la elección o nominación de directivos.

- El grado de transparencia.

- El grado de autocontrol y de subsidiariedad.

Bozeman también indica que las organizaciones pueden ser más públicas con respecto a algunas de su actividades y más privadas respecto a otras.

Evidentemente, dentro de esta dimensionalidad existen muchas modalidades de ONG y de organizaciones mixtas y la tendencia de las administraciones a crear empresas estatales e institutos durante los últimos años ha dado como resultado un panorama todavía más complicado. Sin embargo, se puede reconocer que existe un núcleo de entidades que se enmarcan claramente dentro de los parámetros de cualquiera definición de una ONG, al mismo tiempo que existen otras que por ser más periféricas y presentar problemas de definición no desvirtúan los conceptos fundamentales que separan las ONG del Estado.

En resumen, se trata de un sector ubicado entre la administración estatal y las empresas mercantiles y comerciales, en una sociedad capitalista moderna que ha desarrollado modalidades de asociacionismo y de prestación de bienes públicos con una identidad institucional separada. GuIu ofrece una definición que intenta captar la complejidad y dinámica de las ONG:

-[Son] asociaciones muy diversas que actúan y trabajan al margen del Estado, pero sin los criterios de rentabilidad económica que rigen el mercado de empresas privadas. Constituyen una red dinámica y heterogénea de entidades, a veces situadas muy cerca del sector público oficial -el Estado- a veces celosas de su aprivacidad. y que desarrollan una gama de actividades a menudo concurrentes con muchos servicios que oficialmente suministra el denominado "Estado de bienestar. Se trata de organizaciones no gubernamentales, es decir, en cierto sentido "privadas", pero que normalmente están abiertas a la participación de todos (por tanto, en este sentido "públicas") y que no persiguen la obtención de beneficios económicos sino objetivos como: sensibilizar al conjunto de la sociedad sobre determinados problemas, ofrecer de forma gratuita (o semigratuita) una serie de servicios a determinados sectores de la población o simplemente obtener ciertos tipos de bienes públicos." (1993: 28)

Es importante señalar que tales organizaciones no siempre son altruistas - los grupos radicales anti-aborto norteamericanos podrían ser considerados ONG - y pueden ser dominadas por personas o grupos que las explotan -existen los infames poverty lords (señores de la pobreza) de los barrios marginados de las ciudades norteamericanas que viven de los cánones que cobran de las subvenciones para luchar contra la pobreza o los gestores de colegios profesionales que pervierten los procesos internos para asegurar su control vitalicio-. Tampoco son siempre legales - los grupos pro-derechos humanos en países con regímenes autoritarios a menudo funcionan de manera ilegal y también en las democracias funcionan grupos al margen de la ley-. Esto constituye eel lado oscuro de las ONG (LyONs 1993: 317) que, aunque no reciba mucha atención ni en las investigaciones, ni por parte de los que fomentan el crecimiento de estas organizaciones, es una realidad que debe reconocerse.

Asimismo, pueden ser tanto organizaciones sólidas y complejas - como la ONCE y la Cruz Roja, que aunque tengan un lugar especial dentro del panorama del Estado de bienestar en España, son igualmente ONG - como pequeñas y efímeras cada año nuevas ONG aparecen y otras desaparecen-. Varían no solamente en su magnitud y estabilidad, sino también en su manera de funcionar, sus fuentes de financiación, su sistema de gestión, su estructura legal y, sobre todo, en el tipo de actividades que realizan.

\subsection{Clasificaciones de las ONG}

LIPSKY y RATHGEB-SMITH (1990) ofrecen una tipología basada en tres tipos de organizaciones: las ONG tradicionales de cari- 
dad y de prestación de servicios sociales, las ONG creadas en los últimos veinte anos para responder a la disponibilidad de subvenciones estatales para la prestación privatizada de servicios y las ONG creadas para responder a necesidades no $\mathrm{cu}$ biertas por los servicios disponibles.

Tal definición puede ser útil para clasificar las ONG que se dedican a la prestación de servicios de bienestar, pero evidentemente existen ONG con otras orientaciones. Douglas (1987) ofrece una clasificación de tres categorías: organizaciones para el beneficio de sus miembros (sindicatos, colegios profesionales, clubes deportivos, etc.), organizaciones para el beneficio de terceros (caridades, etc.) y organizaciones políticas (partidos políticos, grupos de presión).

Sin embargo, para captar toda la diversidad de las ONG existentes, la tendencia ha sido de elaborar clasificaciones formales según las funciones sectoriales de las organizaciones. SALAMON y ANHEIER (1992a) repasan las clasificaciones vigentes y ofrecen su propia clasificación, la INCPO ${ }^{10}$ :

\begin{tabular}{lll|}
\hline & \multicolumn{2}{c|}{ Tabla 1} \\
\hline & NCPO (International Classification of NOPs) \\
\hline Grupo & 1: & Cultura y ocio. \\
Grupo & 2: & Formación e investigación. \\
Grupo & 3: & Salud. \\
Grupo & 4: & Servicios sociales. \\
Grupo & 5: & Medio ambiente. \\
Grupo & 6: & Desarrollo económico y vivienda. \\
Grupo & 7: & Organizaciones políticas y grupos de presión. \\
Grupo & 8: & Intermediarios filantrópicos y promoción del voluntariado. \\
Grupo & 9: & Cooperación internacional. \\
Grupo & 10: & Religión. \\
Grupo & 11: & Sindicatos y asociaciones profesionales. \\
Grupo & 12: & Otros. \\
\hline
\end{tabular}

Esta clasificación presenta sus propios problemas de aplicación, tanto por las dificultades para encajar algunas organizaciones, como por las dificultades presentadas por organizaciones que trabajan en más de un sector. La organización ecologista Greenpeace, por ejemplo, se podría clasificar bien en el grupo 5, bien en el grupo 7; si un sindicato -como suele sucederofrece cursos de capacitación puede clasificarse tanto en el grupo 11 como en el 2.

Pese a tales desventajas - y sin entrar en polémicas acerca de las ventajas de esta clasificación sobre las de otros investigadores- puede apreciarse que la clasificación proporciona una visión completa de todas las organizaciones que podrían clasificarse como ONG según las definiciones expuestas anteriormente.
Sin embargo, debe reconocerse que tradicionalmente - si se puede hablar de tradición en un campo relativamente jovenpartidos políticos, sindicatos y la Iglesia, en su labor estrictamente confesional, se tienden a excluir de los estudios sobre el trabajo de las ONG, por mucho que reúnan todas las condiciones para considerarse como tales. La estrecha relación entre los partidos políticos y las instituciones estatales y el lugar privilegiado que ocupan los sindicatos y la Iglesia dentro de la sociedad democrática les separa de las otras ONG.

Asimismo, existe una clara tendencia a concentrarse en las asociaciones que tiene como fin favorecer el bienestar social, la distribución de la riqueza y los derechos sociales y civiles. No es que otras organizaciones -como por ejemplo cámaras de comercio, que tienden a favorecer la acumulación de riqueza en ciertos sectores- sean descartadas como ONG, sino más bien que las definiciones del término han llegado a tener un contenido simbólico mas allá de su estricto valor heurístico. En los países que han regulado las organizaciones de caridad principalmente países de tradición anglosajona - se plasma su definición humanística en leyes que demarcan dichas organizaciones de otras ONG, pero ni siquiera en estos países los intentos de definir las ONG en función de sus propósitos sociales resisten mucho análisis.

A efectos de este artículo, se ha adoptado la definición de Guiu (expuesta en el apartado 3.1.) que incluye esta discriminación en favor de las ONG con objetivos sociales, pero que también admite una amplia gama de organizaciones de orientaciones diversas.

\subsection{Diferencias culturales en el desarrollo de las ONG}

Hasta ahora el comentario sobre las ONG se ha realizado en un contexto neutro, sin referencia a diferencias culturales y nacionales. Sin embargo, es importante señalar que no existe una única definición histórica o transnacional de ONG y que sus funciones, origen y comportamiento en cada país o región reflejan diferencias en las definiciones jurídicas, tradiciones de cultura cívica, ideologías profesionales, relaciones entre la Iglesia y el Estado, niveles de desarrollo económico y políticas estatales (Dimaggio y Anheier, 1990; Kramer, 1981; Salamon y ANHEIER, 1992b; 6 y VIDAL, 1993). La asociación de juristas en un país en vías de desarrollo puede ser el baluarte de los derechos humanos, mientras que en un país desarrollado puede servir únicamente para proteger los intereses comerciales de sus miembros.

La literatura suele señalar que la tasa de asociacionismo en las sociedades anglosajonas es mayor como resultado de una cultura política más indvidualista que favorece la autoorganización al margen del Estado, mientras que en la tradición continental existe una mayor delimitación entre el Esta- 
do y la sociedad civil y una tendencia a dejar la provisión de los bienes públicos en manos de las administraciones. Sin embargo, el auge de las ONG en el continente desde mediados de los años ochenta y la continuada influencia de la literatura norteamericana podría generar un acercamiento entre estos dos bloques de países desarrollados.

No obstante, 6 y VIDAL (1994) mantienen que siguen en vigor tres modelos ideológico-culturales sobre el papel de las ONG:

- Modelo democrático social de un Estado que se ocupa de financiar y prestar servicios sociales y en el que las ONG hacen un seguimiento de los servicios, abogan por servicios nuevos, proporcionan información a los usuarios, facilitan el acceso a los mismos, e impulsan el desarrollo de profesiones del sector del bienestar.

- Modelo norteamericano de participación minimalista del Estado y privatización de la prestación de servicios a través de ONG y empresas privadas. Alto nivel de mecenazgo y otras financiaciones privadas.

- Modelo mixto de provisión de servicios a través de las ONG, pero dentro de un marco normativo estricto.

En el Estado espanol el nivel de asociacionismo ha sido bastante bajo, mermado por la situación económica y política, el papel dominante de la Iglesia, la falta de tradición de voluntariado y de tiempo de ocio y el papel de la familia (VIDAL, 1994). Desde la transición democrática se ha intentado crear en España un estado de bienestar y un tercer sector más fuerte, pero la cobertura global está fuera del alcance de la economía española.

\section{Alcance del sector}

Dadas las diferencias en las definiciones y el interés relativamente reciente de los investigadores por este sector es difícil cuantificarlo con exactitud. La mayoría de países disponen solamente de cifras parciales, además las diferencias terminológicas y nivel de documentación entre países dificultan las comparaciones transnacionales. De todas maneras, las cifras indican que se trata de un sector en crecimiento que acapara un porcentaje significativo de la actividad económica y del mercado laboral.

En los EE.UU - país con tradición de tener un alto nivel de privatización y de una gran actividad de las ONG - existen casi un millón de organizaciones con derecho a los beneficios fiscales de entidades sin ánimo de lucro " (Clotfelter, 1992). La actividad económica de éstas representaba en 1984 un 5.6\% del PBI y un $9.5 \%$ del empleo retribuido y voluntario (DimaGGio y ANHEIER, 1990). En 1988, el 50\% de los gastos de las prestacio- nes sociales federales y el $7 \%$ del presupuesto estatal de Massachussetts se canalizaba a través de las ONG. En la ciudad de St. Louis las ONG representaban el $7 \%$ de la fuerza laboral y el $45 \%$ de los adultos habían colaborado en ellas con trabajo voluntario (LIPSKY y RATHGEB-SMITH, 1990: 626). Asimismo, el sector sigue creciendo mientras que otros sectores de la economía se estancan: el empleo en las ONG creció un $18,3 \%$ entre 1981 y 1987 en los EE.UU, mientras que en el sector privado creció sólo un 7,9\% y en las administraciones un 5,1\% durante el mismo período (Ben Ner y VAN HOOMISSEN, 1990).

En España, los investigadores indican que existe una debilidad en relación a otros países de la Unión Europea y a los países anglosajones (Serra et al., 1989; GarVIA, 1993). De todas formas, la cifras actuales indican que existe un número importante de ONG. GaRviA (1993: 108), citando a LOZA, indica que en 1991 había unas 6.500 eentidades no lucrativas de carácter social y humanitarion en el Estado español y entre 300.000 y 350.000 voluntarios, que representan el $2 \%$ de los trabajadores (lo compara con una tasa del $9 \%$ en Italia). En 1990 existían 91.347 entidades en el registro de la Ley de Asociaciones del Estado (Rodriguez Cabrero, 1993), mientras que en Cataluña había, en 1993, unas 36.098 entidades jurídicas registradas por el Departament de Justicia. Dichas entidades se repartían en las siguientes categorías (Tabla 2) ${ }^{12}$ :

\begin{tabular}{|c|c|c|}
\hline \multicolumn{3}{|c|}{$\begin{array}{l}\text { Tabla } 2 \\
\text { Entidades juridicas en Cataluña, } 1993\end{array}$} \\
\hline Tipo & Nombre & $\%$ \\
\hline Asociaciones y asociaciones juveniles & 21.198 & 58,7 \\
\hline Asoc. deportivas & 7.841 & 21,7 \\
\hline Cooperativas & 5.762 & 16,0 \\
\hline Fundaciones & 741 & 2,1 \\
\hline Federaciones & 249 & 0,7 \\
\hline Mutualidad & 167 & 0,5 \\
\hline Colegios y academias & 140 & 0,3 \\
\hline TOTAL & 36.098 & 100,0 \\
\hline
\end{tabular}

(Fuente: Institut d'Estadistica de Catalunya, 1994)

PorTA (1992) y Marimon (1992), trabajando con datos anteriores, ofrecen más detalles sobre los ámbitos de trabajo de las entidades (Tabla 3).

La situación actual representa un crecimiento importante en los últimos años, pasando de 6.969 asociaciones en 1980 a 21.239 en 1993 (Institut d'Estadística de Catalunya 1995). El Cuadro 1 demuestra el crecimiento en el número de asociaciones registradas en Cataluña entre 1965 y 1993. 


\begin{tabular}{|l|c|c|}
\hline \multicolumn{2}{|c|}{ Tabia 3 } \\
\hline \multicolumn{2}{|c|}{ Ámbitos de las entidades } \\
\hline Tipo & Marimón & Porta \\
\hline Ámbito de la persona & 2.243 & 2.243 \\
Cultura y de difusión & 6.177 & 6.121 \\
Enseñanza e investigación & 3.561 & 3.561 \\
Asistencia social & 1.307 & 1.307 \\
Salud & 249 & 249 \\
Ordenación de espacio, eco. & 1.284 & 1.282 \\
Intereses profesionales & 823 & 823 \\
Deportivos & 6.552 & 6.582 \\
Juveniles & 1.785 & - \\
Fundaciones privadas & - & 445 \\
Cooperativas & - & 6.013 \\
\hline TOTAL & 23.981 & 28.356 \\
\hline
\end{tabular}

Fuente: MARIMÓN, 1992; PORTA, 1992.

\section{Cuadro 1}

Asociaciones registradas en Cataluña, 1965-1993

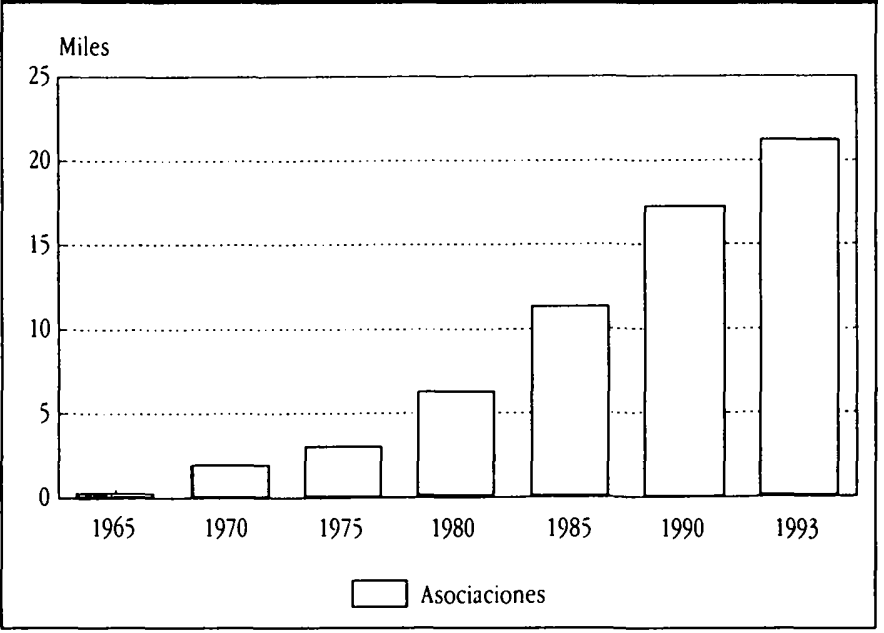

Fuente: institut d'Estadistica de Catalunya (1995)

Estas cifras indican una creciente solidez en cuanto al fenómeno asociativo en este país, que está cada vez más en el camino de tomar una dimensión europea.

No obstante, hay que interpretar las cifras oficiales con cierta cautela, dado que los números brutos no reflejan la realidad de la viabilidad de las organizaciones, ni la de sus actividades; muchas son organizaciones sólidas, bien organizadas y bien fiscalizadas, pero la mayoría son pequeñas y muchas veces efímeras. Un número elevado de las entidades que aparecen en los registros son inoperantes y con frecuencia se tiende a registrar a las que "nacen" y no quitar del registro con igual rigor a las que "mueren. (CIES, 1995). Además, recientes escándalos -como la utilización de la Fundación Quail por el financiero
Javier de la Rosa para proteger sus bienes de embargo judicial- han puesto de relieve que no todas las entidades tienen fines estrictamente benéficos.

Otro indicador sobre las ONG lo constituyen las tasas de participación: una encuesta sobre hábitos de la población indica que el $43 \%$ de la población es socio ${ }^{13} \mathrm{de}$, por lo menos, una asociación, pero entre las diversas asociaciones solamente las deportivas tienen una tasa asociativa significativa (14\%) mientras que las culturales, religiosas, políticas, etc. están todas por debajo del 5\% (Institut d'Estudis Metropolitans de Barcelona, 1992).

\section{Fomento de ONG por parte del gobierno}

Es preciso recalcar que el crecimiento de las ONG en las últimas décadas es el resultado tanto de políticas de fomento de las mismas desarrollados por las instituciones estatales, como de las inquietudes asociativas de la sociedad o de los consumidores de bienes públicos. La antigua lógica de que las ONG eran una molestia para el ejercicio del poder público o de que eran superfluas e ilegítimas dentro de una sociedad democrática va cediendo paso a un apoyo generalizado.

Administraciones, tanto de izquierdas como de derechas, las impulsan a través de subvenciones, contratación de servicios, convenios de cooperación, provisión de infraestructuras, asesoramiento, formación de personal y provisión de marcos legales para su creación, financiación y protección. Sobre todo, las legitiman a través de su integración en consejos asesores y las consagran como interlocutores entre las instituciones y los usuarios. Las administraciones apoyan a las ONG existentes y, a menudo, las crean directamente para llevar a cabo iniciativas claramente institucionales ${ }^{14}$.

Las administraciones asumen -con evidentes matices ideológicos- los criterios en favor de las ONG, citados anteriormente. Fomentar las ONG existentes o crear otras nuevas permite a las administraciones explotar la legitimidad y aceptación de la que aparentemente gozan y aprovechar la eficacia administrativa y económica que parecen ofrecer.

El apoyo institucional, además, asegura un cierto nivel de control sobre las ONG y sobre el flujo de ideas. Las pautas que rigen el destino de las subvenciones dan a las administraciones la posibilidad de imponer sus criterios sobre las actividades de las ONG y una ONG que depende de las administraciones para su financiación y legitimación puede poner éstas en peligro si adopta posturas demasiado críticas. 


\section{Los roles que desempeñan las ONG}

Dada la pluralidad de enfoques sobre el origen de las ONG y su clasificación es de esperar que también existan diferentes perspectivas sobre los roles que desempenan en la sociedad.

Etzioni, en uno de los primeros trabajos escrito en el contexto del neoliberalismo estadounidense, las ve simplemente como una forma eficaz de organización que "combina lo mejor de los dos mundos: eficacia y conocimiento de las empresas y el interés público, la responsabilidad y la perspectiva amplia de la administración" (1973: 315) ${ }^{15}$.

Otros destacan el papel pluralista de las ONG. BerGer y NeuHaus (1977) las describen como "las estructuras mediadoras" que vertebran la relación entre lo público y lo privado dentro de un Estado de bienestar ${ }^{16}$. Kramer (1981) habla de la formación de un tejido de solidaridad que llena el espacio entre el estado democrático y la gente y que permite la intervención en el proceso democrático fuera del cauce clásico e individual del voto. En el contexto catalán contemporáneo, SERRA las caracteriza como ael sistema nervioso de la sociedad democrática; de este sector depende la fortaleza y consistencia de la sociedad civil. (SERRA et alt., 1989). En los últimos años, este análisis se ha extendido hasta el punto que algunos autores consideran que el tejido asociativo es un requisito fundamental de la democracia (SEIGEL y YANCEY, 1992) y los comunitaristas sostienen que una sociedad vertebrada por el asociacionismo constituye el futuro más legítimo de las democracias occidentales, ya que las instituciones estatales han perdido gran parte de su autoridad y capacidad de afrontar los problemas contemporáneos (El País, 1996).

También existen lógicas multidimensionales que intentan determinar los roles de las ONG en función de las ideologías dominantes en la sociedad y el modelo de distribución de competencias entre administraciones y ONG. TAYLOR y LANSLEY (1992) identifican cuatro categorías de ideologías y roles para las ONG, según las relaciones entre la prestación y la financiación de los servicios por parte del Estado o del mercado. Dichas posiciones son: el conservadurismo, el Estado de bienestar, el bienestar pluralista y el pluralismo del mercado (neoliberalismo). La Tabla 4 representa las características de las ideologías y los roles correspondientes de las ONG.

\begin{tabular}{|l|l|l|l|}
\hline \multicolumn{1}{|c|}{ Ideologias y el rol de las ONG } \\
\hline \multicolumn{1}{|c|}{ Ideologia } & \multicolumn{1}{|c|}{ Servicios financiados por: } & \multicolumn{1}{|c|}{ Servicios prestados por: } & \\
\hline conservadurismo & filantropía & sector privado y voluntariado & $\begin{array}{l}\text { comparten prestación de servicios con el sector privado; } \\
\text { la financiación depende del mecenazgo; las élites deciden } \\
\text { políticas para las que necesitan servicios. }\end{array}$ \\
\hline Estado de bienestar & Estado & Estado & rol residual; políticas decididas por el sistema parlamentario. \\
\hline bienestar pluralista & Estado & tercer sector & $\begin{array}{l}\text { prestan servicios; participan en el proceso decisorio, pero este } \\
\text { rol puede ser incompatible con la prestación. }\end{array}$ \\
\hline pluralismo del mercado & clientes y el mercado & sector privado & rol residual; políticas decididas por elección de los clientes. \\
\hline
\end{tabular}

Fuente: Elaboración propia, adaptada de TAYLOR y LANSEY (1992)

SUBIRATS y GOMÀ (1993) ofrecen una visión similar, basada en las diferentes posiciones político-ideológicas sobre las adminis- traciones locales que ordenan las relaciones predominantes en la arena política y el rol de las ONG (Tabla 5):

\begin{tabular}{|l|l|l|l|}
\hline \multicolumn{5}{|c|}{ Administración local y el rol de las ONG } \\
\hline \multicolumn{1}{|c|}{ Posiciones político-ideológicas } & \multicolumn{1}{|c|}{ Rol del gobierno local } & \multicolumn{1}{c|}{ Relaciones predominantes } & \multicolumn{1}{c|}{ Rol de las ONG } \\
\hline neoliberalismo local & residual & competencia & ninguno \\
\hline comunitarismo local, institucionalismo & habilitador & cooperación & operativo instrumental \\
\hline comunitarismo local participativo & capacitador & participador & decisional \\
\hline
\end{tabular}

Fuente: de Subirats y Gomi (1993). 
Pero es difícil caracterizar tan nítidamente el rol de las ONG, ya que muchas de ellas no respetan el papel que les asigna la ideología dominante. Como señalan SuBiRATS y Gomà, da dinámica que deriva de las densas relaciones que se configuran progresivamente entre las ONG y los poderes públicos locales probablemente supere por sí sola la disyuntiva anterior (1993: 42).

En todas estas perspectivas se pueden identificar cuatro roles fundamentales: 1) prestar servicios, 2) innovar, 3) guardar los valores democráticos del sistema, y 4) abogar por el cambio de políticas y/o la mejora de servicios (Kramer, 1981). Aunque es este último rol el que quiero analizar más a fondo, quiero recalcar que los otros tres contribuyen a crear el clima de legitimidad y autoridad que permite que las ONG también asuman un rol político.

\subsection{Prestar servicios}

La prestación de servicios que realizan las ONG es el rol que más atención ha recibido, tanto desde la perspectiva que intenta explicar el crecimiento que han experimentado, como desde la que intenta mejorar su gestión.

Dentro de toda la gama de servicios y bienes públicos, el trabajo de las ONG se concentra en los servicios denominados de "calidad de vida" -educación, bienestar, cultura, medioambiente, y ocio-. En cambio, otros servicios y bienes se han mantenido como propios del Estado - defensa, orden público y relaciones exteriores - o tienen una participación más fuerte de empresas privadas -infraestructuras, energía y comunicación-.

Los que impulsan la prestación de servicios a través de ONG consideran que éstas tienen la capacidad de ser más sensibles a las necesidades sociales de base y de responder a ellas de una manera más eficaz, eficiente e innovadora. Sin embargo, otros advierten que las ONG también pueden perpetuar servicios de segunda clase y ocultar áreas de debilidad en la prestación de bienes sociales (MONTAGUT, 1993).

La mayor parte de la prestación de servicios de las ONG está costeada bien por las administraciones - tanto directamente a través de la contratación de servicios específicos como por subvenciones que apoyan el trabajo central de la entidad-, bien por los mismos usuarios que pagan por el servicio prestado.

\subsection{Innovar}

Muchos autores sostienen que las ONG asumen el papel de viveros para desarrollar proyectos nuevos de acción pública.

Este rol es una consecuencia lógica de las perspectivas economicistas. Si el origen de las ONG se sitúa en la necesidad de cubrir la edemanda no cubierta y el contrato incompleto', la razón de ser de las ONG es, precisamente, la de crear servicios o de reivindicar la elaboración de políticas donde no las haya. SALAMON' (en RATHGEB-SMITH y LIPSKY, 1993: 30) sostiene que para cubrir el fracaso del mercado, el sector del voluntariado -las ONG - organiza nuevos bienes colectivos, y que sólo si luego se produce un efracaso del voluntariado que tampoco logra cubrir las necesidades con voluntarios, las administraciones los subvenciona.

También las perspectivas politológicas y sociológicas sobre las ONG les atribuyen este papel innovador, que derivaría de dos factores primordiales:

- La ausencia de ataduras burocráticas que acotarían el impulso de las innovaciones.

- La concentración en las ONG de gente activista con espíritu «empresarial.

Sin embargo, algunos comentaristas ponen en entredicho la capacidad de innovación de las ONG. Kramer (1981: xix) sostiene que no son innovadoras y que los gobiernos innovan por igual. Se cuestiona también si existe una capacidad autóctona de innovación o simplemente una manera de organización institucional que muchas administraciones adoptan para esquivar la reglas de la burocracia que han heredado. Según Kramer (1981: 225) el plantear ideas en las ONG para que ayuden a introducir cambios en políticas es una estrategia habitual de las administraciones.

\subsection{Preservar los valores democráticos}

Como ya hemos visto en las declaraciones de BERGER y Neuhaus (1977), Kramer (1981) y SerRa (1989), se afirma que las ONG velan por los valores de una sociedad democrática -valores tales como el altruismo, la integración social, la autoayuda, la cooperación, el pluralismo y la participación-y protegen los intereses de las minorias.

Sin embargo, tales afirmaciones tienden a tener un carácter tautológico si sólo se definen las ONG según los valores humanísticos de su fines. Una definición más amplia nos permite identificar muchas ONG cuyo interés por preservar los valores democráticos es escaso. Se refiere no solamente a las organizaciones plenamente anti-democráticas, sino también a toda ONG que busca un particularismo de interés para su comunidad ${ }^{17}$. Así, por ejemplo, la tendencia NIMBY (not in my backyard - no en mi vecindario-) utiliza el asociacionismo para rechazar la presencia de servicios sociales tachados de indeseables por los habitantes de ciertas zonas.

Hasta en su trabajo de "preservar los valores", las ONG a veces se valen de prácticas poco transparentes y poco respe- 
tuosas a dichos valores en la toma de decisiones y en la distribución de los fondos que recaudan. En algunos casos el comportamiento poco ético de las ONG ha dado lugar a intentos de auto-regulación. El código deontológico del National Charities Information Bureau ${ }^{18}$ sugiere que no se utilicen más de un $40 \%$ de dichos fondos para infraestructura y gestión central no directamente relacionada con el servicio (NCIB, 1988).

Además, algunas ONG pecan de los mismos vicios de afán de protagonismo y de rivalidad que las instituciones públicas o el sector privado. En algunos campos existe un cartel de organizaciones poderosas que acaparan las subvenciones y los canales de comunicación con las administraciones y que suelen trabajar tanto para preservar su hegemonía de cara a otras ONG, como para velar por los intereses de sus clientes.

\subsection{Abogar por el cambio de politicas y/o la mejora de servicios}

Las actividades de lobby de las ONG son las que se emprenden con el propósito de influir en las políticas y actividades de las instituciones estatales y de otros organismos públicos ${ }^{19}$. A través tanto de la cooperación con las instituciones como de la presión sobre ellas, las ONG intentan lograr una participación significativa como actores en el proceso de elaboración y ejecución de políticas públicas. La cooperación se define por las actividades en que las ONG actúan como "SOcios" de las administraciones, colaborando en los procesos institucionalizados de elaboración de políticas, de seguimiento y, si las ONG la asumen, de prestación de servicios. En cambio, en el trabajo de presión, las ONG toman una actitud más beligerante, la de forzar cambios desde "fuera del sistema". Se puede equiparar este rol con el trabajo de los llamados grupos de presión ${ }^{20}$.

Sin duda se han producido éxitos sonados: movilizaciones populares vertebradas a través de ONG que logran sus objetivos; organizaciones profesionales que arrancan acuerdos de las administraciones sobre cambios importantes en los servicios donde sus miembros trabajan; consejos asesores que provocan cambios significativos de políticas; actores extra-gubernamentales que siguen imponiendo su criterio contra viento y marea. Pero, más allá de las anécdotas, resulta difícil valorar el rol político y reivindicativo de las $O N G$.

La primera observación que debe hacerse para contextualizar el trabajo político de las ONG es que, generalmente, muestran un mayor interés por intervenir, primero, en lo que se puede denominar las primeras fases ${ }^{21}$ de la elaboración de las políticas públicas -los procesos de identificación del problema y de toma de decisiones sobre las alternativas de acción-y, luego, en las fases finales - la evaluación y reformulación de políticas ya existentes-. Por definición, los intentos de influir en las acciones públicas van dirigidos a convencer -0 a obligar- a los actores institucionales a implicarse en un área o tema desatendido o a cambiar una política existente. Se dan varios ámbitos de intervención: tradicionalmente se intentaba influir en el proceso legislativo, pero con la ampliación de la acción pública, el foco de participación se ha desplazado hacia la intervención en la conducta de las administraciones (ALDERMAN, 1984; WOODWARD et alt., 1985).

La intervención de las ONG debe partir de unos cimientos sólidos de legitimidad política y cognoscitiva $\multimap$ sea, deben tener la capacidad de demostrar que gozan de un amplio apoyo político y que dominan la teoría y práctica de la política en cuestión-. En lo político, puede crearse una base política en el apoyo de la población de base, los usuarios de los servicios públicos y la opinión pública, así como en el de las élites políticas y los técnicos directivos. En cuanto a los recursos cognoscitivos, pueden alcanzar niveles de conocimiento técnico realmente competitivos si mantienen al día sus conocimientos directos de los problemas que afectan a la población objeto. Además deben disponer de los recursos y las habilidades necesarios para manejar el "juego" de participación.

\subsubsection{La cooperación}

La cooperación se canaliza a través de comisiones, consejos y otros procesos formales de representación, consulta y seguimiento que incluyen tanto organismos de enlace entre las administraciones y otros actores, como otros procedimientos democráticos tales como alegaciones a los proyectos de ley o de normativas. El aumento del número de actores ha venido acompañado por un incremento de los órganos de enlace entre administraciones y actores extra-gubernamentales (HuGHES, 1994). Las administraciones ainvitan" a las ONG a participar en dichos órganos que pueden estar constituidos solamente por actores extra-gubernamentales o pueden agrupar una variedad de actores gubernamentales, semi-gubernamentales y extra-gubernamentales.

Existe el debate sobre la conveniencia o no de la cooperación con las instituciones a través de la prestación de servicios y de la participación en los órganos consultivos. Están los que sostienen que la participación se traduce en un mayor prestigio y una mayor proximidad a la administración, lo que concede, por tanto, más posibilidad de participar en la elaboración de políticas que les afecten. El incremento de la presencia, a través de la participación, de las ONG conlleva un incremento correlativo de la capacidad de influencia porque confiere legitimidad y da derecho a influir en los procesos decisorios. A través de la prestación de servicios las ONG consiguen tener acceso a los clientes y, por tanto, conocer sus necesidades.

Por el contrario, otros sostienen que dichas colaboraciones no son más que mecanismos de control institucional. Las admi- 
nistraciones crean los órganos consultivos, los regulan y proporcionan los recursos para su funcionamiento, lo que les permite valerse de ellos tanto para mantener abiertos canales de diálogo sustantivo entre actores, como para evender políticas previamente decididas o para evitar críticas. Además, mantienen que la consecuencia lógica de este tipo de participación es el clientelismo y que, en vez de formar un bloque independiente de control, los criterios de las ONG se van acercando cada vez más a los de la administración. Las normativas y pautas que vienen impuestas a través de las subvenciones implican control externo sobre la manera de actuar de las ONG (RANCI, 1993) y muchas de éstas sse dejan comprar. (Roelofs, 1987) o simplemente evitan :morder la mano que las alimenta.

\subsubsection{La presión}

La alternativa a cooperar es presionar. Existen vías judiciales y otros canales institucionales, como el defensor del pueblo, que permiten un cierto grado de presión adentro del sistema. A la vez existe una amplia gama de tácticas de presión no institucionalizadas, tanto las que se dirigen directamente a las administraciones como las que tienen la finalidad de crear un clima de opinión favorable a un punto de vista u otro. Estas tácticas incluyen: la movilización de fuerzas sociales (manifestaciones), financieras (boicots) o industriales (huelgas); acciones espectaculares para captar la atención de la opinión pública; la publicación de informes o la creación de "noticias" para poner en evidencia una situación no deseada; acciones directas, como campañas de envíos de cartas, para presionar a los decisores; $y$, ya en otro nivel más extremo, existen las acciones ilegales y el terrorismo. Algunas ONG utilizan las tácticas citadas con gran habilidad y las que trabajan en áreas conexas habitualmente coordinan sus esfuerzos a través de coordinadoras y coaliciones para maximizar recursos y ampliar su base política.

Las ONG que optan por presionar y, por tanto, de mantener una relación más conflictiva con las administraciones evidentemente han de asumir los costes inherentes a tal relación. En algunos países existen restricciones legales sobre el trabajo de presión de las ONG (RANDON y 6, 1994), pero las sanciones más contundentes que tienen a su alcance las administraciones son la retirada de subvenciones y la marginación política de las ONG consideradas más beligerantes. Muchas ONG funcionan aal filo de la navaja" y mantienen con las administraciones un continuo tira y afloja que les permite mantener una actitud de presión, pero sin cruzar la raya que podría significar la marginación política y/o la pérdida de todo apoyo financiero de las instituciones.

\subsection{3. ¿Cooperar o presionar?}

La elección de estrategias de cooperación o presión podría estar condicionada por una combinación de factores: a) El grado de universalismo de los bienes y servicios públicos y el nivel de marginación o discriminación de la población de la que se trata. Si se considera que no existe una prestación equitativa de servicios se tendrá que abogar por ampliarla a la población no atendida o por crear servicios específicos dirigidos a ella; en el caso de poblaciones que sufren alguna forma de discriminación se tendrá que reivindicar un trato equitativo. Por definición, las ONG que abogan por estos cambios se encuentran al margen de las administraciones y tienen que recurrir preferentemente a tácticas de presión. En cambio, si los bienes y servicios son universales, el rol de las ONG - aparte de la participación en la prestación de los mismos servicios- puede ser más el de ejercer un control y seguimiento para asegurar la calidad. Para conseguir tales objetivos podrían valerse preferentemente de estrategias de cooperación.

b) La orientación de la cultura política en la que operan. La elección de estrategias puede variar de país en país en función del sistema y de las tradiciones políticas vigentes. Según Kramer (1981), en los EE.UU se recurre con frecuencia a los medios de comunicación, a las manifestaciones y a las contribuciones a campañas políticas, mientras que en Inglaterra y Holanda se trabaja más a partir de comunicaciones informales entre individuos ${ }^{22}$. En los EE.UU. las ONG se concentran, principalmente, en trabajar directamente con los legisladores, mientras que en otros países las ONG dirigen su trabajo de presión a las administraciones.

c) La doctrina política y las afiliaciones partidistas e institucionales. Las ONG pueden escoger estrategias en función de su relación política con el partido en el poder, las relaciones institucionales y/o la ideología de la organización. Algunas ONG son por sus convicciones políticas más propensas a pelear, mientras que otras prefieren los pactos y el diálogo.

La relación entre las ONG participativas y las que son más propensas a mantener solamente actitudes de presión admite distintas interpretaciones. Por un lado, la participación de algunas ONG refuerza la marginación del proceso decisorio de las que mantienen su oposición a las políticas institucionales, pero, por otro, la presencia de aradicales" puede reforzar el poder negociador de las moderadas que buscan desde dentro cambios en las políticas actuales.

Sean cuales sean sus estrategias y tácticas, las ONG deben tener la capacidad organizativa para desempeñar con éxito este papel multidimensional. Para ser eficaces en su rol político las ONG deben tener la capacidad de vigilar al gobierno, influir en la elaboración o renovación de la legislación, presionar para lograr mejoras en los servicios de las administraciones y asegu- 
rarse los fondos para mantener sus propios servicios. Han de ser críticas y polivalentes, los eperros guardianes ${ }^{23}$ de la acción pública.

\subsection{4. ¿Tienen éxito las ONG en su rol de actores en el proceso de elaboración de políticas públicas?}

Como se ha señalado anteriormente, las ONG tienen un mayor interés para intervenir en las fases de identificación y definición (o de re-identificación y re-definición) de problemas de acción pública, siendo precisamente en este papel donde se constata el impacto de las ONG. Según Jenkins (1987), las ONG tienen más éxito influyendo en la opinión pública, llevando problemas a la agenda de los decisores, y valorando programas existentes que determinando la forma de implementación de las políticas o el funcionamiento de las administraciones.

Los resultados son difíciles de medir: dependen, por una parte, del grado de pluralismo y apertura del sistema y, por otra, de las habilidades y los recursos de los actores. "Para que los grupos marginados puedan influir en las políticas públicas hace falta mucha cohesión, disciplina y eficacian. (ACOSS, 1993: 7).
Asimismo, la falta de transparencia de los procesos decisorios, así como el afán de protagonismo de las instituciones y su necesidad de legitimar el modelo legislativo-representacional sirven para obscurecer la posible influencia que podrían haber tenido las ONG en la elaboración de una política concreta.

No obstante, a nivel anecdótico y experiencial, existen amplios testimonios de las avictorias ; tal como declara un manual para la formación de técnicos de ONG:

.Políticos y otros decisores pocas veces hacen algo por su propia cuenta. Son 'veletas', sujetos al cambio de los vientos. Si soplas fuerte, girarán en tu dirección. (CMTS, 1984: 98).

Estas afirmaciones siguen alentando a las ONG a organizarse para participar en los procesos de cooperación y para ejercer su derecho a utilizar tácticas de presión. Donde existe apertura aprovechan las posibilidades de participación que se les ofrece; donde no existe presionan para que la haya. La fe en la eficacia y trascendencia de implicarse en la elaboración de las políticas públicas fomenta la aparición de nuevos actores e impulsa las propuestas para potenciar la gestión de los recursos políticos y cognoscitivos al alcance de las ONG (ACOSS, 1993; SMUCKER, 1991).
- Esta investigación ha sido parcialmente financiada por el proyecto - Grupo de Calidad. del Equipo de Análisis Política de la UAB, a través de una subvención del Commissionat d'Universitats $i$ Recerca de la Generalitat de Catalunya.

- Departament de Ciència Política i de Dret Públic. Universitat Autònoma de Barcelona.

1 Véase el apartado 3, para la justificación de la elección del término •organización no gubernamental. Actualmente se utiliza Más para identificar a las organizaciones de cooperación internacional que para las que se dedican a la prestación de servicios locales. La elección de dicho término, por tanto, también sirve para reivindicar su uso edoméstico.

2 En España, por ejemplo, existía ya en 1849 una Ley General de Beneficencia que regía las .fundaciones de acción social o benéfico-asistenciales.

3 En junio de 1994, la recientemente constituida International Society for Third Sector Research (Organización Internacional para la Investigación sobre el Tercer Sector) celebró su primer congreso en Pécs, Hungría, con el objetivo de agrupar la investigación en este campo. Actualmente en España un número reducido de personas - la ISTR tiene alrededor de 15 socios espanooles pero ninguna delegacióntrabaja con poco contacto entre ellos.

4 En inglés, contract failure.

'Économie sociale-que incluye los colectivos económicos-y community services sector-que se define por los servicios prestados y no por el carácter económico o social de las entidades- son los términos que más se diferencian de los otros. Este artículo no abarca directamente el papel de los colectivos o de las empresas privadas que prestan servicios comunitarios.

6 Véase Lohmann (1987) para una discusión de las diferencias entre los términos norteamericanos y SALAMON y ANHEIER (1992) para un análisis de términos y clasificaciones.

${ }^{7}$ Cada país suele tener definiciones legales de ONG, sobre todo para definir las organizaciones que tendrán ventajas fiscales.
${ }^{8}$ Hablo aqui de definiciones de $\cdot l o$ público $y \cdot l o$ privado sobre todo en un sentido político-jurídico. Véase WOLCH (1990) para una discusión de los mismos conceptos en sentido ético, económico, sociológico y antropológico.

9 Algunos autores hablan de un ecuarto sector: las relaciones informales y la familia (EVERS, 1993, en AA.VV. 1993b: 129), pero no se incluirá una discusión de ello en este trabajo).

${ }^{10}$ International Classification of Nonprofit Organizations (Clasificación Internacional de Entidades Sin Ánimo de Lucro). Cada grupo de la clasificación es desglosado en subgrupos que pormenorizan la tipología.

"Registradas bajo la sección 501(c)3 de la ley de hacienda estadounidense.

12 Algunos investigadores catalanes sostienen que en Cataluña hay un tejido asociativo más denso que en otras partes de España. Según su argumento, dicho tejido es el resultado de la falta de una Administración Pública propia que pudiera representar los intereses de la sociedad civil catalana, la cual veía, por tanto, la necesidad de autoorganizarse para defenderlos (CASTiNera, 1992; PORTA, 1992). Declaraciones en este sentido son frecuentes en textos sobre el asociacionismo en Cataluña, pero los autores no ofrecen datos empíricos para defender su hipótesis.

${ }^{13}$ La encuesta sólo documenta el hecho de ser socio y no el de la participación activa.

${ }^{14}$ El término inglés QUANGO, Quasi-Autonomous Non-Government Organizations, describe las empresas estatales que se crean por decreto, pero que utilizan la forma organizativa de ONG.

15 ETzION hablaba fundamentalmente de crear empresas grandes del tercer sector que podrian hacerse cargo de bienes públicos como la seguridad social, los préstamos a estudiantes, la formación, etc.

${ }^{16}$ Son las estructuras mediadoras formales. Se habla también de estructuras informales como la familia, las redes de amigos, etc.

${ }^{17}$ Estas ONG reivindican bienes privados o especificos en vez de bienes públicas universales. 
is Centro nacional de información sobre entidades caritativas de los EE.UU.

19 Las ONG también intentan influir en el trabajo de entidades privadas, tanto directamente como indirectamente a tracés de la regulación por las instituciones. Este artículo se limita a la intervención en el sector público.

¿ Los grupos de presión se anticulan a través de varias modalidades organizativas -p.ej., consultoras privadas, $\mathrm{ONG}$, redes informales, etc.-. Este articulo abarca solamente el trabajo de las ONG que desempeñan el papel de grupos de presión.

"Véase las perspectivas sobre los aciclos- de elaboración de políicas públicas. JONES (1984), por ejemplo, sostiene que el proceso sigue las siguientes fases: 1) definición del problema y su inclusión en la agenda pública, 2) formulación de alter- nativas y toma de decisiones, 3) legitimación de las decisiones, 4) presupuestación, j) ejecución de las intervenciones concertadas y 6) evaluación. Dicha evaluación casi siempre conlleva una reformulación de algunos aspectos referentes a las otras fases, resultando de ello la creación de nuevos ciclos de reformulación de políticas y respuestas institucionales. Véase también SuBIrats (1989) para una discusión en castellano sobre los ciclos.

"2 Kramer indica que en Inglaterra el old boys' network (red de ex-alumnos de escuelas privadas) sigue siendo un canal importante de comunicaciones informales.

${ }^{23}$ Del inglés watcb dogs.

\section{Bibliografia}

AA.V.(autores varios) (1990), Documentación Administrativa (numero especial: -Politicas públicas y organización administrativa.), Instituto Nacional de Administración Pública, 224-225, Madrid.

(1992a), Ponencias presentadas al seminario Management of Interorganizational

Networks en la conferencia de la European Consortium for Political Research, Limerick, Ireland, March 30 - April 4, 1992 (mimeos).

(1992b), Ponencias presentadas a las jornadas L'associacionisme: espai, realitat i perspectives, L'Hospitalet, mayo 1992, Institut Municipal d'Associaciones i Esplais (IMAE), Barcelona. (mimeos)

(1993a), Revista del CIFA (Centre d'Investigació Formació i Assessorament (número dedicado a las ONG), Patronat Flor de Maig, Diputació de Barcelona, núm. 12, Barcelona.

(1993b), Well Being in Europe by Strengthening the Third Sector, abstracts de la conferencia en Barcelona, mayo 1993, Centre d'Iniciatives de l'Economia Sucial, Barcelona.

(1993c), Papers d'Educació d'Adults (nimero dedicado al voluntariado) vol. 20, Associació d'Educadors de Persones Adultes, Barcelona.

(1994b), En Pie de Paz (nümero dedicado al voluntariado), vol. 3, núm. 32. ACOSS (Australian Council of Social Services) (1993), Influencing Public Policy: The ACOSS View ponencia del director a una conferencia sobre políticas publicas, 17-5-93 (mimeo).

Alderman, Geoffrey (1984), Pressure Groups and Government in Great Britain, Longman, New York.

ANHeIER, Helmut K. y Wolfgang SeIBEL (eds.) (1990), The Third Sector: Comparative Studies of Nonprofit Organizations, de Gruyter, New York.

Ben-Ner, Avner y Tetesa VAN Hoomissen (1990), . The Growth of the Nonprofit Sector in the 1980s: Facts and Intepretation, en Nonprofil Management and Leadership, vol. 1 , núm. 2.

Berger, Peter. L. y Neuhaus, Richard. J. (1977), To Empower People: The Role of Mediating Structures in Public Policy, American Enterprise Institue for Public Policy Research, tambien reproducido en Gies David. L et alt. (eds.), op. cit.

Bozeman B. (1987), All Oryanizations are Public, Jossey-Bass, San Francisco.

CASEY, John (1995), ¿Por qué reiuindicamos la gestión privada de la protección social?, ponencia presentada en las Jornades Internacionals de Serveis Socials de la Generalitat de Catalunya, Barcelona. (mimeo)

Cast7ñelra, Angel (1992), -La societal civil. en AA.VV. 1992b, op. cit. (mimeo).

CIES (Centre d'Iniciatives de l'Economia Social) (1995) Mapa de Catalunya de ESALs. 1993, CIES, Barcelona.

Clotfelter, Charles T. (1992), Who Benefits from the Nonprofit Sector?, University of Chicago Press, Chicago.

CMTS (Community Management Training Scheme) (1984), Stepping Stones; Crossing the River of Local Group Despair: A Management Training Manual for Community Groups, CMTS, Sydney.

CONTINENTE, Marta (1992), -Tecniques per afavorir les relacions amb les institucions., en AA.VV. 1992b, op. cit. (nimeo)
DiMagGio, Paul J. y Helmut K. Anheier (1990), -The Sociology of Nonprofit Organizations and Sectors, en Annual Review of Sociology, 16, pp. 137 - 159.

DouGLAS, James (1987), ·Political Theories of Nonprofit Organizations* en Walter W. Powell, op. cit.

DruCKer, Peter F. (1990), Managing the Non Profit Organization, Harper Collins, New York. (versión castellana: Dirreción de instituciones sin fines de lucro, El Ateneo, Buenos Aires).

El Pais (1996), . El voluntariado no es una alternatva al Estado de bienestar: entrevista a Amitai Eizioni, $7 / 2$.

Etzıon, Amatai (1973) The Third Sector and Domestic Missions, en Public Administration Review, pp 314-323.

GaRVIA, Roberto (1992), .Mutual Dependence between Government and Private Service Monopoly: The Case of the Spanish Blind, en Kuhnle S. y P. Selle (eds.), Government and Voluntary Organizations, Avebury, Aldershot.

GIES, David L. et alt. (eds.) (1990). The Non Profit Organization: Essential Readings, Brooks/Cole Publishing, Pacific Grove CA.

GuIU Payà, Jordi (1993), -Entre públic i privat: un espai per a l'interès comú. en AA.VV. 1993a, op. cit.

Hansmani, Henry (1987), •Economic Theories of Nonprofit Organization, en Walter W. Powell, op. cit.

HenIG, Jeffrey R. (1990), PPrivatization in the United States: Theory and Practice, en Political Science Quarterly, vol. 104, núm. 4.

HOOD, Christopher y Gunnar Folke SCHUPPERT (1988), Delivering Public Service in Western Europe, Sage, London.

HuGHes, Owen E. (1994), Public Management and Administration: An Introduction, MacMillan Press, London.

Institut d'Estadistica de Catalunya (1995), Anuari 1994, Institut d'Estadística de Catalunya, Barcelona.

Institut d'Estudis Metropolitans de Barcelona (1992), Enquesta de la Regió Metropolitana de Barcelona 1990, Universitat Autònoma de Barcelona.

Jenkins, J. Craig (1987), •Nonprofit Organizations and Policy Advocacy• en Walter W. Powell, op. cit.

JONES, Charles O.(1984), An Introduction to the Study of Public Policy, 3rd. Edition, Brooks/Cole Publishing, Monterey.

Kramek, Ralph M. (1981), Voluntary Agencies in the Welfare State, University of California Press, Los Angeles.

LIPSKY, Michael y Steven RATHGEB-SMrTH (1990), Nonprofit Organizations, Government and the Welfare State. en Political Science Quarterly, vol. 104, núm. 4, pp. 625-648.

Lohmanv, Roger A. (1993), ·The Commons: A Multidisciplinary Approach to Nonprofit Organization, Voluntary Action, and Philanthropy. en Nonprofit and Voluntüry Sector Quarterly, vol. 21, pp. 309-323.

Lyons, Mark (1993), The History of Non-Profit Organizations in Australia as a Test of Some Recent Non-Profit Theory. en Voluntas, vol. 4 núm. 3, pp. 301-325.

Marimon, Francesc Xavier (1992), ·Reflexió de l'associacionsime i l'administració autonomica a Catalunyar, en AA.VV. 1992b, op. cit. (mimeo). 
Mouns LOPEZ-RoDó, Joaquín M. (1992), Los grupos de interés en España, Papeles de la Fundación Núm. 7., Fundación para el Analísis y los Estudios Sociales, Madrid.

MontaGuT, Maite (1993), -El voluntariat als serveis socials, en AA.VV. 1993c, op. cit.

NCIB (National Charities Information Bureau) (1988), Standards in Philantbropy, NCIB, New York.

Petrus, Antoni (1991), Estudi comparat sobre el voluntariat, Dirreció General D'Acció Civica, Generalitat de Barcelona.

PORTA, Jordi (1992), La realitat associativa a Catalunya - en AA.VV. 1992b, op. cit. (mimeo).

Powell, Walter W. (ed.) (1987), The Nonprofit Sector - A Researcb Handbook, Yale University Press.

Rancl, Constanzo (1993), The Role of the Third Sector in Welfare Policies in Italy. en AA.VV. 1993b, op. cit., pp. 180 - 182.

RANDON, Anita y PeRRI 6, 'Constraining Campaigning: the Legal Treatment of NonProfit Policy Advocacy across 24 Countries' en Voluntas, vol. 5 núm. 8, pp. 27-58.

RATHGEB-SMITH, Steven y Michael LIPSky (1993), Non Profits for Hire. The Welfare State in the Age of Contracting, Harvard University Press, Boston.

Rodríguez Cabrero, Gregorio (1993), -La coordinación interasociativa: el sector voluntario en AA.VV. 1993a, op. cit.

RoELofS, Joan (1987), .Foundations and Social Change Organizations: The Mask of Pluralism, en The Insurgent Sociologist, vol. 14, núm. 3.

Salamon, Lester M., y Helmut K. ANHEIER (1992a), -In Search of the Non-Profit Sector I: the Question of Definitions, en Voluntas, vol. 3, núm. 2, pp. 125-151.

y Helmut K. ANHeier (1992b), .In Search of the Non-Profit Sector II: the Problem of Classification, in Voluntas, vol. 3, núm. 3, pp. 267-309.
SeiGel, Dan y Jenny Yancey (1992), The Rebirth of Civil Society: the Nonprofit Sector in East Central Europe, Rockerfeller Brothers Fund, New York.

6, Perrl y Victor A. Pestoff (1993), Research in the Third Sector in Europe: Directions and Prospects, (mimeo que acompaǹa AA.VV. 1993b, op. cit.)

e Isabel VIDAL (eds.) (1994), Delivering Welfare: Repositioning Non-Profit and Cooperative Action in Eestern-European Welfare States, Centre d'Iniciatives de l'Economia Social, Barcelona.

SerRa, Albert, Pep Marti y Xavier Bonal (1989), El sector no lucratiu a Barcelona: una primera aproximació, INITS, Barcelona.

SMUCKER, Bob (1991), The Nonprofit Lobbying Guide, Jossey Bass, Washington.

SuBirats, Joan (1989), Análisis de politicas püblicas y eficacia de la Administración, Ministerio para la Administraciones Públicas, Madrid.

(1992), •Administración pública y mercado, en Información Comercial Española, núm. 712, pp. 33 - 42.

y Ricard Gomi (1993), Lla elaboración pluralista de la políticas locales: el papel de los ONG., en AA.VV. 1993a, op. cit.

TAYLOR, Marilyn y John LANSLEY, (1992), .Ideology and Welfare in the UK Voluntary Sector. en Voluntas, vol. 3, núm. 2, pp. 153-174.

VIDAL, Isabel (1994), . Non-Profit Organisations in the Administration of Social Services in Catalunyar, in 6 y VIDAL, op. cit. (versión en catalán: Les entitats sense anim de lucre en la gestio dels servies socials a Catalunya, mimeo)

(1995), Mapa de Catalunya de entidades sin animo de lucro 1993, Centre d'Iniciatives de l'Economia Social, Barcelona.

Wol.CH, Jennifer R. (1990), The Shadow State: Government and Voluntary Sector in Transition, The Foundation Center, New York.

WoOdward, Dennis, Andrew Parkin y John Summers (eds.)(1985), Government. Politics and Power in Australia, Longman Cheshire, Melbourne. 